\title{
Historiku i hapjes së Normales përmes burimeve arkivore
}

Majlinda PEZA-PERRIU

Një shekull e një dekadë, duket një kohë e gjatë, por që sot sjell pikërisht në vëmendjen tonë, kushtet dhe rrethanat historike, kur në Elbasan u bënë bashkë patriotë e intelektualë ${ }^{1}$ dhe arritën që vendimet e Kongresit të Elbasanit të mos mbeteshin thjesht të shkruara në letër, por të përmbushnin një mision të shenjtë, hapjen e së parës Shkollë Normale. Ata patriotë e intelektualë elbasanas, duke qenë të ndërgjegjshëm për pengesat e vështirësitë tepër të mëdha, morën përsipër që Normalja të hapej në Elbasan. Kërkesat për mësues të gjuhës shqipe vijonin të ishin të mëdha në vitet 1908 - 1909 . Që në qershor të vitit 1909 Simon Shuteriqi, nën pseudonimin "Ura e Shkumbinit”, shkruante se: “... mësimore duam të çelim, po mjerisht mësonjës të zotët të marrin përsipër këtë punë të lartë, mësonjës që të munt të mësojnë me systemë gjuhën tonë, dhe ta dijnë këtë mbë një shkallë të mjaftë, përgjithësisht të thomi na mungojnë ${ }^{2}$. Ishte Kongresi i Elbasanit në të cilin u vendos që një javë pas mbylljes së punimeve të tij, më 14 shtator 1909 të hapej në Elbasan Shkolla Normale ose siç u quajt në dokument "Mësonjëtorja e mësonjësve".

Sa e vështirë do të ishte hapja në kushtet e atëhershme e një shkolle Normale dhe të çfarë natyre do të ishin pengesat që do të shfaqeshin në hapjen e saj?

Pikërisht, duke marrë në konsideratë vlerësimet e diplomatëve të huaj për këtë problem, hapja e një shkolle Normale në atë kohë rezultonte thuajse e pamundur. Konsulli austro-hungarez i Manastirit shfaqej tepër dyshues

1 E vetmja grua pjesëmarrëse në Kongresin e Elbasanit, por pa të drejtën për të marrë pjesë në diskutimet e Kongresit ka qenë Sevasti Qiriazi, ndërsa e motra e saj Parashqevi Qiriazi ka qenë e vetmja grua që ka marrë pjesë në Kongresin e Manastirit.

"Tomorri", nr. 10, Elbasan, 10 qershor 1909, autori Simon Shuteriqi me pseudonimin Ura e Shkumbinit. 
për zbatimin e vendimeve të Kongresit të Elbasanit duke u shprehur se: “Nëpërgjithësi mund të themi se Kongresi i Elbasanit nuk do ti plotësojë aspak shpresat që kanë tek ai për çështjet kulturale, për arsye se zbatimi i vendimeve të Kongresit dhe sidomos hapja e një normale qysh në fillim do të hasë në vështirësi materiale." Duhet thënë se një pohim i tillë, fillimisht gjeti konfirmim përmes faktit se, Shkolla Normale nuk u hap në datën e përcaktuar nga Kongresi i Elbasanit dhe as në datën e lajmëruar nga "Këshilli Mbikëqyrës" i Normales, pra as në 14 shtator 1909 dhe as më 16 nëntor sikurse ishte shpallur nga "Këshilli mbikqyrës".

Por, vështirësitë nuk do të ishin vetëm financiare dhe materiale. Një ndër problemet që kërkonte zgjidhje të menjëherëshme lidhej me gjetjen e mësuesve, të cilët duhej të ishin të aftë profesionalisht për të dhënë mësim në gjuhën shqipe. Në këtë kontekst, informohemi për ftesën që L. Gurakuqi i drejtonte Aleksandër Xhuvanit, duke i kërkuar të bëhej pjesë e stafit të Normales përmes fjalëve: "Duke të njohur vlerat si gjuhëtar, mësues patriot i përkushtuar, un këmngul që ti të jesh pjesë e shkollës tonë kombëtare, sepse kjo shkollë ka nevojë për njerëz si ju dhe besoj që ftesa ime të pranohet”." I entuziazmuar për përgjigjen pozitive të Aleksandër Xhuvanit, ai do të vijonte edhe më pas të shkruante se: "Jam shumë i lumtur shkruante ai në letrën e datës 24 tetor 1909 që Aleksandri më dëgjoi arsyet e mia dhe që të jetë dhe ai pjesë e shkollës Normale” ${ }^{2}$. Kështu, Aleksandër Xhuvani u emërua si mësues i gjuhës shqipe në Shkollën Normale të Elbasanit. Ai ishte diplomuar në shkencat filologjike, kishte punuar si profesor i gjuhës shqipe në kolegjin e Arbëreshëve të Italisë në San Dometrio Korone dhe ishte bërë i njohur në fushën e studimeve gjuhësore përmes botimeve të ndryshme në shtypin e kohës. Aleksandër Xhuvani do të jepte mësim në lëndët gjuhë shqipe, histori dhe gjuhë frënge. Gjthashtu, stafi pedagogjik i parë i Normales përfaqësohej nga intelektualë të shquar në fushën e arsimit kombëtar. Intelektualët e parë elbasanas që dhanë mësim në Normale përfaqësoheshin nga Petër Dodbiba, Simon Shuteriqi, Hasan Mezja, Dhimitër Paparistoja dhe Hafiz Ibrahim Dalliu nga Tirana. Gjithashtu, në cilësinë e të dërguarit të federatës shqiptare "VATRA" të Bostonit, ishte Sotir Peci një nga mësuesit e shquar të shkollës Normale i diplomuar në Greqi për matematikë - fizikë dhe i njohur si drejtor i gazetës "Kombi"".

3 AQSH, F. Luigj Gurakuqi, Dos. 55, letër e datës 24 tetor 1909.

4 Po aty.

5 Charles Telford Erickson, Shqiptarët Enigma e Ballkanit, vëll. Il, përgatit Mal Berisha, Edualba 2012, f.116. 


\section{Albanon}

\section{Revistë kulturore}

Kështu, pas shumë përgatitjesh dhe pasi u kapërcyen jo pak pengesa e probleme të natyrave të ndryshme organizative dhe financiare, vështirësitë e para të organizimit në hapjen e Normales do të rezultonin të përkohshme. Patriotët shqiptarë dhe elbasanas duke patur dhe mbështetjen e popullit të Elbasanit, arritën të hapnin në Elbasan, të parën shkollë të mesme në gjuhën shqipe. Ceremonia e hapjes u bë në 1 dhjetor të vitit 1909, ndërsa procesi i rregullt mësimor filloi më 2 dhjetor të vitit 1909. Një ngjarje e tillë ishte rezultat edhe i kontributit të pandërprerë për një periudhë afro tre mujore e "Këshillit Mbikqyrës" të Normales dhe shoqërisë "Përparimi“. Fillimisht Normalja u hap në ndërtesën e Servet Bej Zylfit, sikurse kishte vendosur Kongresi i Elbasanit dhe e filloi aktivitetin e saj me një kapacitet prej 50 nxënësish. Pas 3 muajsh, konstatohet një dyfishim i numrit të nxënësve dhe në fund të vitit mësimor, numri i tyre arriti në 150 nxënës. Një pjesë e këtyre nxënësve edhe pse mund të ishin në vitin e fundit në shkollat e tyre, përsëri i braktisën ato për të kaluar në shkollën Normale ${ }^{6}$.

Ndërkaq, me fillimin e mësimit në shkollën Normale, mësuesit e shkollës do të përballeshin me vështirësi të reja që konsistonin në këto drejtime kryesore:

Së pari, viti i parë mësimor filloi duke huazuar dhe përdorur plane mësimore nga vendet më të zhvilluara perëndimore, por duke qenë shumë larg në praktikë për sa i përket bazës materiale që ofronin këto shkolla. Ndërkaq, mësuesit e shkollës nuk zotëronin asnjë tekst si burim shkencor për shpjegimin e koncepteve të ndryshme, duke e rritur shkallën e vështirësisë në përcjelljen e lëndës tek nxënësit. Një problem i tillë, pasqyrohej në atë kohë në organet e shtypit kombëtar ku në një thirrje që u bëhej intelektualëve shqiptarë e sidomos mësuesve të Normales së Elbasanit, thuhej: "Bekim $i$ madh e lumturi e paanët do të jetë për kombin tonë në qoftë se secili prej të diturit tonë do të punojë për ndonjë të këtillë vivllë, dhe veçan profesorët e shkollës Normale, se prej tyre kombi pret dritën e madhe e jo vetëm për çunat që gjenden në këtë skoli, por edhe për gjithë ata që mësojnë, ose të mëdhenj janë këta, ose të vegjël” 7 . Kështu, mungesa e teksteve mësimore, bëri që fillimisht mësuesit të jepnin materialet mësimore me shënime, por një metodë e tillë ulte shumë cilësinë dhe rendimentin e mësimdhënies. Telford Erickson, shprehej se ishte gjetur një zgjidhje, ku si shumëfishues të mësimeve shërbenin poligrafët. Ndërsa, Aleksandër Xhuvani shkruante se, "mësimet fillimisht nisën me të shkruar, por kjo gjë e ulte rendimentin e orës së mësimit, duke e vështirësuar

6 AQSH, F. “Lef Nosi”, Dos. 50, fl. 1.

7 "Historia e arsimit dhe mendimit pedagogjik shqiptar", vëll. I, Tiranë: 2003, 88-89. 
proçesin mësimor si për nxënësit ashtu edhe për mësuesit. Për të zgjidhur këtë problem, u porosit në Selanik një poligraf, me qëllim shumëfishimin e mësimeve të pregatitura nga mësuesit dhe më pas shpërndarjen e tyre nxënësve”. Sipas kujtimeve të Aleksandër Xhuvanit veprohej në këtë mënyrë: “...Ishte e para herë që gjithë lëndët mësimore po bëheshin në gjuhën shqipe dhe e mbaj mend se kemi heqë mundë të madh tue $i$ hartue e tue i shkrue gjithë lëndëte mësimeve shqip e tue ua spiegue nxanësvet". Mësimet i shkruanim me dorë, kujton Aleksandër Xhuvani, në formën e dispencave; "pastaj letrën e shkruar e shtrinim përmbi një dërrasëpak të fellë katërkandëshe, të ndërtueme për këtë qëllim, së cilës $i$ shtrihej mbrenda një farë lande e bardhë si pelte, që vinte së jashtmi. Shkrihej kjo landë në zjarr dhe shtrihej në ato dërrasa, ku ngrinte mbas një copë herë; prej shkrimit që ngulej aty nga letra e shkrume nxirreshin nga 50 e 60 kopje për çdo mësim, që dilshin kthjellët e lexoheshin mirë, e kështu ua shpëndajshim nxanësve. Kësi dërrasash kishim shumë, nga një për çdo mësim. Me këtë mënyrë u arrit të mënjanohej forma e diktimit në shpjegimin e mësimeve që në fazën e parë».

Së dyti, një problem tjetër shumë i rëndësishëm, kishte të bënte me kontigjentin e nxënësve të ardhur në shkollë, që për shkak të nivelit të pamjaftueshëm të njohurive të gjuhës shqipe të këtyre nxënësve, nuk mundësonte funksionimin si Normale të shkollës. Në vendimet e Kongresit të Elbasanit dhe në rregulloren e shkollës Normale të miratuar prej tij, parashikohej që kjo shkollë të kishte 6 klasë, ku tri klasë të ishin përgatitore dhe tri klasë thjesht normale. Por nga vendimi që u mor nga "Këshilli Mbikëqyrës" në vitin e parë u hapën katër klasë, ku tre prej të cilave ishin përgatitore dhe vetëm një ishte normale. ${ }^{9}$ Por, në dhjetor të vitit 1909 Aleksandër Xhuvani, shkruante se: "Mjerisht nuk gjetëm element për të parin rend të Normales u detyruam pra që të mbajmë sivjet vetëm tri rendet e shkollave premtare"(përgatitore)". Kështu, në momentin që erdhën nxënësit e parë, u konstatua që mund të hapeshin vetëm 3 klasa të kursit "premtar". Në kursin "premtar" do të hynin nxënësit që kishin mbaruar vetëm shkollën fillore, ndërsa në klasën e dytë dhe të tretë do të hynin ata nxënës që kishin kryer edhe klasë më të larta në shkollat qytetëse ose dhe të mesme të huaja.

Kështu, pavarësisht faktit se pjesa më e madhe e nxënësve që u regjistruan në Normale kishin studiuar më parë në shkolla të huaja, rezultonte se shumë prej tyre dinin të shkruanin dhe të lexonin në shqip. Por, kishte dhe nga ata nxënës që nuk kishin pasur mundësi që në mënyrë klandestine ta mësonin

8 AQSH, F. 3. Dos. 29, fl. 148.

9 Gazeta "Bashkimi i Kombit", nr.6, Manastir, 15 vjeshtë e II, 1909, f. 2. 


\section{Albanon}

\section{Revistë kulturore}

atë. Në këtë kuadër, për të krijuar kushte më të favorshme në mësimdhënie, "Këshilli Mbikëqyrës" vendosi që të hapte provizorisht një kurs të veçantë 3-4 mujor, enkas për këta nxënës që të mësonin të shkruanin e të lexonin shqip, që më pas të kalonin në klasën e parë të "premtares". Gjithashtu, një numër jo i vogël nxënësish shqiptarë u larguan nga shkollat turke për të vazhduar Normalen që gjatë vitit të parë mësimor të hapjes së saj. Ky largim ishte evident edhe në shkollat e Stambollit. Kështu, Ali Çaushi rezulton të ketë qenë i pari elbasanas i cili djalin e tij, e largoi nga gjimnazi turk i Elbasanit (megjithëse në klasë të fundit) dhe e regjistroi në shkollën Normale ${ }^{10}$.

Gjithashtu, përmes faqeve të gazetës "Lirija" informohemi se, në dhjetor të vitit 1910 për të vazhduar mësimet në shkollën Normale u larguan: nga Janina 8 nxënës, nga Delvina 2 nxënës dhe nga Përmeti 2 nxënës. ${ }^{11}$ Në një artikull botuar në gazetën "Zgjimi i Shqipërisë" thuhej se: "Tetë djem shkuan nga idadija e Janinës për në Mësonjëtoren Normale të Elbasanit, pa dhe të tjerë përgatiten të shkojnë. Djemtë që iknë nga idadija iknë nga dëshira që patnë të venë ndë Shkollë Normale të Elbasanit" ${ }^{12}$. Në këtë kuadër, në shkollën Normale filluan studimet nxënës që vinin nga të gjitha trevat shqiptare si nga Prishtina, Gjakova, Peja, Prizreni, Mitrovica, Gjilani, Presheva, Shkupi, Dibra, Struga, Pogradeci, Shkodra, Kruja, Tirana, Gjirokastra, Përmeti, Delvina, Libohova etj. ${ }^{13}$ Parë në këtë këndvështrim, sikurse ishte vendosur dhe nga Kongresi i Elbasanit, lindi si domosdoshmëri ngritja pranë saj e një konvikti që do të funksiononte me pagesë.

Për sa i përket administrimit të financave, në programin shkollor të Normales thuhej se: "Këshilli $i$ Kontrollit ka në dispozicion 100 lira në vit qü do t’i përdorë për të ndihmuar nxënësit ose kandidatët e vobektë. Ata nxënës që duan të banojnë në konviktin e shkollës, do të paguajnë 10 lira në vit. Por Këshilli $i$ Kontrollit... mund edhe ta falë taksën për konvikt. Në këtë rast zbritja e pagesës së konviktit pjesërisht ose e tërë do të mbulohet prej atyre 100 lirave” ${ }^{14}$ Kështu, nga 150 nxënës që kishte Normalja në vitin e parë, 71 prej tyre rezultonin të ishin konviktorë, ndërsa të tjerët të jashtëm. Një pjesë e tyre ishin me dhe pa pagesë. Për ta bërë sa më efektiv mësimin në konvikt u organizua edhe studimi i rregullt për studentët e brendshëm. Ndërkohë, sipas informacionit të konsullit austro-hungarez në Durrës, thuhej se numri i nxënësve të

10 AQSH, F. 102, Dos. 50, fl. 1.

11 Gazeta "Lirija”, 19 shëndre 1909.

12 Gazeta "Zgjim i Shqipërisë", nr.53, Janinë, 30 vjeshtë III, 1909.

13 Gazeta "Tomorri" nr. 2, Elbasan, 20 mars 1910, f. 2: "Lirija”, nr. 84, Selanik, 17 prill 1910, f. 2.

14 HHSTA/PA. Raport i konsullit austro-hungarez të Durrësit, Nr. 19. dt. 27 maj 1910. 
Normales në vitin e parë ishte $160^{15}$. Përveç nxënësve që patën fatin të vazhdonin mësimet në Normale, pati edhe shumë nxënës të tjerë nga vise të ndryshme të Shqipërisë, që shprehën dëshirën dhe kërkuan të regjistroheshin në të. Por këta nxënës nuk u pranuan, për shkak të pamundësisë për t’i strehuar në Elbasan, prandaj dhe mbetën si kontigjent për vitin e ardhshëm shkollor. Për këtë problem konsulli austriak në Durrës shprehej: "Numri $i$ nxënësve sot është aq i lartë sa që në Elbasan nuk mund të gjenden as klasa mësimi të mëdha e të mjaftueshme, por as vende për vendosjen e bursistëve. Sikur të merreshin parasysh të gjitha lajmërimet, që vazhdojnë të bëhen gjithnjë, atëherë do të duhej që në fillim të vitit të ardhshëm shkollor të gjendej vend të paktën për 1000 nxënës, prej të cilëvë 600 konviktorë"16.

Përveç nxënësve që erdhën nga të gjitha rrethet e vendit, pati dhe shumë të tjerë që erdhën nga Kosova. Për të bërë të mundur ardhjen e këtyre nxënësve nga Kosova, një ndihmë të madhe dha atdhetari i njohur Hasan Bej Prishtina. Kuptimplotë dhe me rëndësi është fakti që në vitin e parë shkollor të Normales, 50 nxënës ishin nga Kosova, pra pothuajse $1 / 3$ e numrit të përgjithshëm të tyre. Duhet theksuar se, një punë e madhe në këtë drejtim u bë nga klubet kombëtare dhe patriotët kosovarë, sidomos nga klubi shqiptar i Shkupit dhe Hasan Prishtina, i cili nuk kursente "as kohën, as pasjen e tij" dhe zotohej se do të dërgonte në Normale edhe shumë "shumë të tjerë"17. Hasan Prishtina e çmonte shumë Normalen jo vetëm si një vatër arsimi e kulture kombëtare, por ai e quante Normalen "qendra e parë e vëllazërimit të rinisë shqiptare"18 duke e konsideruar edhe si një vatër politike, ku nxënësit do të mbusheshin plot dashuri për atdheun. Sigurisht që këto nxënës, ashtu si edhe nxënësit e krahinave të tjera, nuk erdhën të tërë njëherësh por në kohë të ndryshme, pothuajse gjatë tërë vitit shkollor. Nxënësit e parë që erdhën nga Kosova ishin 7 djem dhe më pas, gjatë vitit, u pasuan dhe nga shumë të tjerë.

Në shtypin shqiptar të kohës është pasqyruar ardhja e nxënësve nga Kosova, si dhe pritja e ngrohtë që u bëhej atyre nga mësuesit e Normales dhe nga popullsia e Elbasanit. Situata e krijuar në pritjen e nxënësve nga Kosova pasqyrohej përmes fjalëve të L. Gurakuqit, i cili në atë kohë pohonte se: "Nuk asht nevoja t'ua them me gojë, pse as nuk mundem t'ua rrëfenj me fjalë harenë e madhe, që na dëgjon zemra në ditë të sotme; ju vetë ta këndoni më mirë ndë sytë e fytyrat tona, mund ta kuptoni nga kjo shumicë njerëzish, prej më të

15 Po aty.

16 HHSTA/PA. Raport i konsullit austo-hungarez të Durrësit, nr.19, dt.27 maj 1910.

17 Gazeta "Dielli", nr.52, Boston, 25 mars 1910, f. 2. Pseudonimi ishte "Shkam i Letanit".

18 A. Haxhiu, "Hasan Prishtina", Tiranë: 1964, 17. 


\section{Albanon}

\section{Revistë kulturore}

parëve e më të mirëve t' Elbasanit, që ju kanë dalë përpara për t'u pritur..."'19. Gjithashtu edhe në faqet e gazetës “Dielli”, L. Gurakuqi, do të shprehej se: "Ka ardhun një ditë, dhe nuk ash e largët, kur me një dituri të vërtetë dhe me themel, me një arsim krejt kombëtar, do të dritësohet dhe do të marrë rrugën e qytetërimit gjithë ajo Kosovë burrërore, gjithë ai vend $i$ atdheut të dashun, ku kanë shkëlqyer kurdoherë besa më e madhe dhe trimnia më e rrallë, me të cilat asht pajuar kombi shqipëtar"20.

Pavarësisht vështirësive të shumta që u shfaqën në vitin e parë mësimor, falë këmbënguljes dhe përkushtimit profesional të mësuesve, bashkëpunimit me komisonin mbikëqyrës dhe mbështetjes që i dha vetë populli i Elbasanit ditë pas dite e javë pas jave, viti i parë mësimor i shkollës Normale u mbyll me sukses në qershor të vitit $1910^{21}$. Kështu, përfundimi i vitit të parë të Normales nga stafi pedagogjik i saj u konsiderua i suksesshëm. Gjithashtu në raportin që mësuesit e Normales i dërgonin kryetarit të Komisionit Drejtues të saj në 30 qershor të vitit 1910, evidentohej një moment mjaft i rëndësishëm, ai i realizimit me sukses i provimeve të fundvitit pavarësisht se këto provime nga mësuesit paraqitnin një shkallë të lartë vështirësie ${ }^{22}$.

Ndërkaq, kërkesat e shumta për ta vazhduar Shkollën Normale, evidentuan njëkohësisht edhe problemet më të rëndësishme që u shfaqën që në vitin e parë dhe kërkonin zgjidhje në vitin në vazhdim. Një problematikë e tillë, u shndërrua në problem shqetësues për Komisionin Drejtues të shkollës, të përfaqësuar nga kryetari Dervish Biçaku. Më së shumti problematika e parashtruar vinte si rezultat i përvojës së vitit të parë të Normales dhe shfaqej në disa drejtime kryesore:

Së pari, në vitin mësimor në vazhdim, rezultonte si domosdoshmëri sigurimi i një godine më të gjerë si për shkollën Normale ashtu edhe për konviktin e saj, në funksion të kërkesave gjithnjë e në rritje të numrit të nxënësve. Në raportin vjetor të Normales për vitin shkollor 1909-1910, ndërtimi i një godine të re për Normalen konsiderohej si një detyrë tepër emergjente. Për këtë problem, Dervish Biçaku, ende pa mbaruar viti i parë i Normales, kishte planifikuar një udhëtim brenda dhe jashtë vendit me qëllim sigurimin e fondeve të nevojshme për ngritjen e një godine të shkollës Normale. Edhe

19 Murat Gecaj, Normalja e Elbasanit, Universiteti i parë shqiptar vatër e zjarrtë atdhetare për arsimin tonë kombëtar, Tiranë: 2009, 30.

Gazeta "Dielli", nr. 60, Boston, 20 mars 1910, f. 4.

AQSH, F. 3, Dos. 53, fl. 1. 
nënkonsulli austro-hungarez në Durrës ishte i mirinformuar për problemin në fjalë. Në takimin që ai kishte patur me Dervish Biçakun në prill të vitit 1910, shprehej se: “... Një plan për këtë shkollë është projektuar që tashi. Shpenzimet për zbatimin e tij pa orenditë e brendshme do të kapin shifrën 2000 lira turke. Ai Dervish Beu ka ndërmend të filloi mbledhje parash lidhur me sigurimin e kësaj shume"23.

Së dyti, nga stafi drejtues i Normales për vitin e ri mësimor, kërkoheshin mësues të veçantë posaçërisht për ata nxënës, që konsideroheshin të dobët në gjuhën shqipe. Gjithashtu, kërkohej shtimi i numrit të mësuesve për dy rendet e para të premtares dhe për rendin e parë të Normales. Kërkesa të vazhdueshme bëheshin edhe për shtimin e mjeteve mësimore në funksion të rritjes së nivelit pedagogjik dhe shkencor. Por çështja më kryesore nga ku do të varej përmbushja e kërkesave të sipërpërmendura, vijonte të ishte sigurimi i mbështetjes financiare të nevojshme, për të vazhduar rregullisht procesi mësimor në shkollën Normale në vitin në vazhdim.

Por, zhvillimet politike në vitin 1910, bënë që Normalja të mos hapej në vitin mësimor pasardhës. Në shtator të vitit 1910, në Elbasan ishte shpallur gjendja e jashtëzakonshme dhe qyteti mbahej i rrethuar nga trupat osmane. Si rezultat i një situate të tillë, shumica e patriotëve elbasanas dhe mësuesve të shkollës Normale, për t’i shpëtuar raprezaljeve të ekspeditës së Turgut Pashës u larguan jashtë vendit. Të tillë ishin Luigj Gurakuqi, Aleksandër Xhuvani, Dervish Biçaku, Aqif Pashë Elbasani etj. Ata që mbetën u keqtrajtuan fizikisht ose u internuan në Anadoll. Lef Nosi drejtuesi i gazetës “Tomori” u internua në Bursë, ndërsa Simon Shuteriqi u keqtrajtua fizikisht. Përveç tyre edhe patriotë të tjerë të Elbasanit pësuan të njëjtin fat.

Në këto rrethana, pavarësisht, mendimeve dhe përpjekjeve të patriotëve shqiptarë për të hapur Normalen në një vend tjetër jashtë Shqipërisë, nuk u arrit asgjë në këtë drejtim. Ndërkaq, zhvillimet politike në trevat shqiptare, në vitet 1911-1912, ndikuan dukshëm edhe në lëvizjen arsimore duke penguar dhe hapjen e Normales, e cila përkohësisht hapi dyert e saj dy muaj para se të mbaronte viti mësimor 1911-1912 (në prill të vitit 1912). Ndërsa pas shpalljes së pavarësisë, Normalja u rihap po në qytetin e Elbasanit në fund të shtatorit të vitit 1913 deri në maj të vitit 1914 sikurse edhe më pas, do të vijojë të mbetet gjithmonë në Elbasan. Jo më kot kjo shkollë historikisht është njohur si Normalja e Elbasanit dhe gjithashtu edhe qyteti i Elbasanit si qyteti i Normales.

23 HHSTA/PA, raport i nënkonsullit austro-hungarez të Durrësit nr. 19, 27 maj 1910. 